\title{
Demanda clínica em psicoterapia de família: Arte-Diagnóstico Familiar como instrumento facilitador
}

\author{
Rebeca Nonato Machado \\ Terezinha Féres-Carneiro \\ Andrea Seixas Magalhães \\ Pontifícia Universidade Católica do Rio de Janeiro, Rio de Janeiro-RJ, Brasil
}

Resumo: Este estudo teve como objetivo descrever a aplicação do Arte-Diagnóstico Familiar (ADF) como um instrumento de avaliação e construção da demanda familiar na clínica. Cada membro da família vem à primeira entrevista com objetivos e motivações próprias. É função do psicoterapeuta auxiliar a família a perceber sua demanda no transcorrer das entrevistas, procurando aproximar as motivações individuais de cada integrante, a fim de criar uma demanda conjunta. Por meio da análise de um caso clínico foi possível identificar a contribuição do ADF no processo de avaliação da família.

Palavras-chave: Arte-Terapia. Entrevista psicodiagnóstica. Avaliação psicológica. Estudo de caso.

\section{Clinical demand in family psychotherapy: Family Art Evaluation as a facilitator instrument}

\begin{abstract}
This study describes an application of the Family Art Evaluation (FAD), an instrument to assess and to construct family clinical demand. Family members arrive to the first interview with their own goals and motivations. It is the psychotherapist's function to help the family to perceive their demand along the interviews, trying to approximate individual motivations so to create a conjoint demand. It was possible, during the analysis of a case study, to identify the contribution of FAD to the family assessment process.
\end{abstract}

Keywords: Art Therapy. Psychodiagnostic interview. Psychological assessment. Case study.

\section{Demanda clínica en la psicoterapia de familia: Arte-Diagnóstico Familiar como instrumento facilitador}

Resumen: Este estudio tuvo como objetivo describir la aplicación del Arte-Diagnóstico Familiar (ADF), como un instrumento de evaluación y construcción de la demanda familiar en la clínica. Cada miembro de la familia viene a la primera entrevista con sus propios objetivos y motivaciones. Es la función del psicoterapeuta ayudar la familia a darse cuenta de su demanda, buscando aproximar los motivos individuales de cada miembro de la familia, para así crear una demanda conjunta. Por un análisis de caso fue posible identificar la contribución del ADF en el proceso de evaluación de la familia.

Palabras clave: Arte-Terapia. Entrevista psicodiagnóstica. Evaluación psicológica. Estudio de caso. 
O início de uma psicoterapia, seja ela individual ou familiar, é um momento delicado que exige atenção e um sensível manejo por parte do psicoterapeuta. Os primeiros encontros são diferenciados do processo psicoterapêutico, sendo denominados entrevistas preliminares e fazem parte do método clínico (Bleger, 1980/2001). Os objetivos e características deste período inicial são específicos: a investigação do histórico de vida do sujeito, a reflexão sobre o pedido de ajuda - o que está por trás da queixa manifesta - assim como a definição do diagnóstico e a indicação da psicoterapia.

Em alguns casos, torna-se necessário recorrer a instrumentos de avaliação confiáveis, a fim de que os resultados enriqueçam e contribuam para a construção da avaliação diagnóstica. Na clínica de família, os instrumentos de avaliação mais usados são: o Arte-Diagnóstico Familiar (ADF) (Kwiatkowska, 1975), a Entrevista Familiar Estruturada (Féres-Carneiro, 2005) e o Genograma (McGoldrick \& Gerson, 1985). Eles auxiliam na avaliação do nível de promoção de saúde familiar, mas também podem contribuir para a elucidação da demanda na clínica, que muitas vezes é manifestada de forma confusa pela família.

Para que o processo psicoterapêutico seja iniciado, é preciso estar claro para a família a importância de sua realização. Por isso, a construção de uma demanda familiar torna-se fundamental para o estabelecimento do tratamento, tendo em vista que cada membro vem à primeira entrevista com objetivos e motivações próprias. Muitas vezes não sabem definir suas expectativas em relação ao tratamento e o discurso coletivo apresenta-se confuso. Cabe ao psicoterapeuta a função de auxiliar a família a perceber sua demanda no transcorrer das entrevistas, durante as quais se realiza uma reflexão sobre os objetivos da consulta, procurando aproximar as demandas individuais de cada membro, a fim de que se crie uma demanda familiar/conjunta (Eiguer, 1985). Este artigo buscou descrever o uso do ADF no trabalho clínico com uma família, e demonstrar como se deu a passagem da queixa inicial para a demanda conjunta em terapia de família.

\section{Entrevistas preliminares: período de avaliação familiar}

$\mathrm{Na}$ primeira entrevista é preciso estabelecer um contato empático entre o psicoterapeuta e os integrantes da família, basicamente porque o primeiro encontro, tanto com a família como com um paciente individual, desperta angústia e ansiedade, talvez pela artificialidade de expor conflitos a um estranho. De acordo com Mannoni (1965/2003), esta ansiedade e angústia emergem, não apenas pelo fato de o psicoterapeuta ser a pessoa a quem a família recorre, após tentativas fracassadas e ilusões perdidas, mas também por ser aquele que "denunciará" seus aspectos disfuncionais.

Stierlin, Rücker-Embden, Wetzel e Wirsching (1980/1995) afirmam que o trabalho empático do psicoterapeuta depende, principalmente, de sua capacidade de alcançar uma visão do conjunto, do sistema e de saber mantê-la ao longo do tratamento. É preciso haver não só uma visão, mas também uma escuta do conjunto/sistema. Os autores ressaltam que na terapia de família os aspectos individuais não devem ser desvalorizados, eles devem ser respeitados como tais, porém encontram-se contidos no sistema familiar.

No entanto, a família não consegue perceber os processos circulares patológicos, na medida em que se trata de mecanismos inconscientes, ou parcialmente inconscientes, cabendo ao psicoterapeuta de família acentuá-los e trabalhá-los. Talvez esta seja uma das tarefas mais difíceis do psicoterapeuta, pois, muitas vezes, a família vem ao consultório com a estrutura muito fragilizada e fragmentada, dificultando criar uma demanda familiar/conjunta.

Nas primeiras sessões, a família tende a falar somente daquilo que a incomoda. Para Stierlin e cols. (1980/1995), os psicoterapeutas principiantes, devido à inexperiência, são induzidos a focar somente as perturbações e a patologia mencionadas no discurso manifesto do grupo, deixam de investigar também os recursos funcionais da família, que fundamentam a avaliação do prognóstico. Portanto, é fundamental pesquisar tanto os conflitos e aspectos disfuncionais quanto os recursos e potenciais da 
família; assim como indagar sobre as tentativas que ela realizou para superar dificuldades. Elucidar os aspectos promotores de saúde, nas entrevistas preliminares, possibilita à família acreditar em suas capacidades funcionais, para que possa ver a possibilidade de mudança onde aparentemente não há.

Uma das especificidades das entrevistas preliminares com famílias é a necessidade de atenção às suas regras, mitos e segredos, reconhecendo a força homeostática, cuja função é estabilizar a dinâmica familiar. É importante a presença de todos os membros da família, até mesmo das crianças, para que se possa observar a função de cada um. No final do processo de avaliação, o clínico deve elaborar uma hipótese sobre a função do sintoma na configuração da trama familiar, para que um trabalho psicoterapêutico seja delineado. Todavia, esta hipótese deverá ser sempre questionada e revisada.

A fim de preencher as lacunas de informações da primeira entrevista, marca-se uma próxima, podendo incluir até mesmo a terceira geração da família, se for necessário para obter mais informações. Deve-se estabelecer um acordo com a família, envolvendo as expectativas, as metas e a dinâmica das sessões, ora poderá ser atendido o casal, ora o subsistema fraterno. O objetivo do contrato é conscientizar a família de que há um problema familiar comum, que afeta todos os seus integrantes, e como o processo psicoterapêutico poderá ajudá-los.

A dinâmica do grupo familiar, assim como a entrevista inicial com a família e o diagnóstico, são concebidos, neste artigo, a partir das abordagens psicanalíticas e sistêmicas, dado que considera-se que a articulação entre tais perspectivas é mais pertinente para a eficácia de um tratamento familiar. Vários autores postulam que os enfoques sistêmicos e psicanalíticos se complementam na clínica de família e casal (Féres-Carneiro, 2008; Féres-Carneiro \& Ponciano, 2005; Lemaire, 2007; Rabelo, 2008; Willi, 1993). Propõe-se aqui uma tríplice chave de leitura que considere o intrapsíquico, o interacional e o social (Lemaire, 1984).

\section{Início de psicoterapia: da queixa à demanda}

Para entrar em psicoterapia é preciso que o sujeito se perceba implicado no problema e na queixa e que, ao questionar seu sofrimento e sintoma, reconheça-se envolvido no tratamento. Ou seja, o compromisso do paciente com a psicoterapia ocorre quando ele se implica naquilo de que se queixa, sentindo-se participante da situação desencadeadora de seu conflito interno.

Cabe ao psicoterapeuta ajudar o paciente a transformar o pedido de ajuda em demanda de tratamento. Na visão de Rocha (2000), o período de entrevistas permite ao psicoterapeuta "situar-se diante do tipo de demanda que lhe faz o entrevistado" (p. 30). Segundo o autor, o reconhecimento do sofrimento leva o sujeito a buscar ajuda e desejar mudança. No entanto, este desejo é ambivalente e a psicoterapia pode ser vivenciada como uma ameaça. O sentimento de ameaça acontece porque a mudança psíquica pode ser ameaçadora, posto que o sintoma é a "solução" que o psiquismo encontrou para sobreviver ao conflito psíquico.

Para Rocha (2000), é preciso que haja desejo de compreender o significado do sintoma, e que inconscientemente o paciente saiba que este significado, ainda incompreensível, está no interior de si mesmo. Diante do incompreensível, o sujeito busca um interlocutor que é o psicoterapeuta. Trata-se, portanto, neste período de avaliação, de elucidar a "queixa" e possibilitar que se construa a demanda. A partir da reflexão sobre a prática clínica, tanto individualmente quanto com famílias, pode-se concluir que é preciso haver esta passagem da queixa à demanda, para que tanto o paciente individual quanto a família se comprometam com o tratamento. Stierlin e cols. (1980/ 1995) enfatizam que este processo dependerá da disposição do paciente para confrontar-se consigo mesmo, a qual surge a partir da pressão do sofrimento.

Segundo estes autores, na terapia familiar, o psicoterapeuta deve estar capacitado a reconhecer e a mobilizar os recursos improdutivos no conjunto familiar, que envolvem a falta de disposição para a ação, a ambivalência do desejo de confrontar-se com as questões familiares e a dificuldade de suportar a realidade. Entende-se que o psicoterapeuta familiar deve explicitar estas dificuldades à família, ressaltando que as mudanças dependem deles mesmos, da motivação familiar ambivalente e do que é denominado pelos autores de "sabotagem encoberta". Para Eiguer 
(1985), na psicoterapia de famílias a ambivalência é mais clara e inflamada, devido ao fato de muitas vezes haver discordância entre seus membros com relação a querer, ou não, a psicoterapia.

Não é tarefa fácil construir a demanda conjunta, até porque na maioria das vezes a família vem com a queixa direcionada a um membro do grupo, depositando nele a patologia da trama, pois não consegue discernir que o sintoma apresentado por um membro denuncia os conflitos familiares. Mannoni (1965/2003) afirma que o psicoterapeuta irá ajudar a família a articular sua demanda, constituindo-a em palavras, a partir da história familiar de origem, e decifrará a mensagem do sintoma. O psicoterapeuta não dará significado aos transtornos e sim ao mundo inconsciente do sistema familiar. Para que o tratamento aconteça, é preciso que o psicoterapeuta acredite na possibilidade de se firmar um contrato entre ele e a família que o procura, e que aposte na capacidade reflexiva desta, oferecendo condições necessárias para que seja capaz de formular sua demanda conjunta (Morandi, 2006).

\section{Técnica de avaliação: Arte-Diagnóstico Familiar}

Féres-Carneiro (1975) ressalta que o diagnóstico familiar deve ser um diagnóstico interacional, que considere a família como sistema homeostático. O sintoma de um membro deverá ser considerado um sintoma da patologia familiar. Recorrer às técnicas de avaliação diagnóstica nas entrevistas preliminares vai além do objetivo de diagnosticar a patologia da família, uma vez que elas também são um facilitador para a adesão da família à psicoterapia. O psicoterapeuta deve sentir-se confortável em aplicar as técnicas de avaliação, escolhendo qual ou quais serão aplicadas, de acordo com o contexto de cada família. A finalidade da aplicação deve estar clara para o profissional: avaliar a interação familiar, conhecer a história da família, constituir um vínculo terapêutico, elucidar a demanda familiar, estabelecer a adesão dos membros ao tratamento e implicar a família na efetuação de mudanças.

OArte-Diagnóstico Familiar foi desenvolvido por Hanna Kwiatkowska, professora de arte-terapia da Universidade George Washington e da Washington
School of Psychiatry, nos Estados Unidos da América. A autora criou uma técnica de avaliação, utilizada no período de entrevistas, cuja linguagem terapêutica baseia-se em desenhos com temas pré-determinados. A família expressa, por meio da arte, sua capacidade de criatividade, de flexibilidade e de integração, apresentando sua distribuição de papéis e suas formas de comunicação, assim como a dinâmica de seu funcionamento.

A construção desse instrumento foi gradual, passando por diversas modificações e sendo submetido a várias pesquisas. Somente após muitos anos de estudos, finalmente, estruturou-se o ADF como instrumento de avaliação confiável e imparcial. A partir das pesquisas realizadas, concluiu-se que o material artístico espontâneo, produzido nas sessões com as famílias e com os pacientes psicóticos, ajudava os membros familiares e os psicoterapeutas a entenderem melhor os problemas familiares (Kwiatkowska, 1978).

As tarefas que compõem o ADF foram inspiradas em desenhos que apareciam naturalmente nas sessões de arte-terapia familiar. Observou-se que, ao desenvolvê-los, as famílias freqüentemente traziam temas em comum que estimulavam ricas discussões familiares. O ADF consiste na estruturação de seis tarefas realizadas em apenas uma sessão, com todos os membros possíveis da família, até mesmo a presença das crianças pequenas mostra-se importante para revelar segredos e a dinâmica familiar. Esta técnica permite obter também dados referentes às interações, separações, dominação, submissão, retraimento, dentre outros aspectos, de membros da família ou subsistemas. Para a realização dos desenhos, são utilizados cavaletes formando um semicírculo no setting, de modo que todos os membros da família possam ver os desenhos dos demais e comentá-los. Em cada cavalete há uma prancha com seis folhas de papel de tamanho $18 \times 24$ cm e uma caixa com lápis cera de cores variadas. Após cada etapa, pede-se à família para retirar a folha usada.

Em todos os desenhos deverão ser observados os comportamentos verbais e não verbais, as interferências feitas nos desenhos dos outros e a ordem de finalização dos desenhos (quem termina primeiro ou por último). A família é convidada a expressar-se livremente, é pedido para cada membro assinar, datar e dar um título às respectivas criações. 
A seqüência das tarefas propostas por Kwiatkowska $(1971,1978)$ é a seguinte: (a) Primeiro desenho livre; (b) Retrato da família; (c) Retrato da família abstrata; (d) Rabisco individual; (e) Rabisco em conjunto; (f) Segundo desenho livre. Essa seqüência é de fundamental importância, pois cada tema pode provocar afetos intensos e estressantes, sendo trabalhados no desenho posterior, como por exemplo, na criação do Retrato da família abstrata, tarefa durante a qual o nível de ansiedade e estresse pode se intensificar. Por isso, logo após esta etapa, faz-se um exercício de relaxamento, pedindo aos membros da família que façam movimentos com os braços e criem um rabisco no ar, desenhando-o em seguida no papel.

De acordo com Kwiatkowska (1978), a primeira e a última tarefa foram inspiradas na técnica criada por Elionor Ulman, psiquiatra norte-americana que foi pioneira ao pesquisar sobre o uso da arte no diagnóstico psiquiátrico. O primeiro desenho, Primeiro desenho livre, é onde se registram as primeiras tensões do grupo familiar: pede-se que os membros da família "façam um desenho daquilo que vier à cabeça, que desenhem qualquer coisa que tenham vontade" (Kwiatkowska, 1978, p. 86).

O tema da segunda tarefa foi inspirado na freqüência com que os membros familiares desenhavam espontaneamente a família. O Retrato da família favorece discussão espontânea, quando é pedido a eles que "façam um desenho de sua família, cada pessoa, incluindo você mesmo" e que "façam um desenho da pessoa toda" (Kwiatkowska, 1978, p. 87). Nesse desenho, podem surgir várias perguntas relativas a quem incluir e como desenhar, devendo ser incentivado que seja criado da forma como a pessoa prefira. Ao terminarem, é solicitado que identifiquem cada membro desenhado.

Um momento que gera muita interação entre os membros da família é quando são solicitados a criar o terceiro desenho: Retrato da família abstrata. Esta tarefa é a mais difícil de ser explicada, e a que leva mais tempo para ser realizada, pois não é fácil de ser elaborada nem mesmo para as famílias mais integradas. Ela tem como objetivo colher informações simbólicas de cada membro. Pede-se que façam outro desenho da família, distinguindo cada membro, incluindo o próprio sujeito. No entanto, não devem desenhar rostos ou corpos, mas usar somente cores e formas para representar o que pensam ou sentem a respeito de cada membro da família.

De acordo com Touson (2002), médico e psicoterapeuta argentino, as cores representam uma forma idônea de se conhecer o inconsciente e o mundo interior do sujeito. Ele justifica a importância das cores devido a sua presença em tudo que nos é visível. Elas são portadoras de conteúdos e significados complexos, que vão além da escuta e da observação sobre a representação do objeto. Desde a escolha da cor até a intensidade do traço, pode-se analisar a expressão espontânea das emoções do sujeito. A partir das considerações deste autor, pode-se afirmar que o uso de cores e formas, na terceira tarefa do ADF, é bastante adequado para representar abstratamente cada membro da família.

O Rabisco individual é a quarta tarefa e oferece uma avaliação individual de cada membro familiar. Solicita-se que façam um rabisco no ar, depois desse movimento livre, solicita-se que cada um fique diante de sua folha, feche os olhos e faça o mesmo tipo de rabisco no papel. Depois do rabisco feito, pedese que olhem o rabisco e vejam que imagem parece emergir deste, desenhando-a em seguida.

O clímax de ansiedade do grupo familiar se dá no quinto desenho, Rabisco em conjunto, quando são dadas as mesmas instruções do rabisco individual, mas com uma diferença. Solicita-se ao grupo que escolham o rabisco e criem um desenho em conjunto. É importante o mínimo de interferência do psicoterapeuta, com o objetivo de deixar a família muito à vontade. Nesse desenho é solicitado que decidam também o título e a forma de assinarem juntos.

Por fim, o último desenho solicitado, Desenho livre, tem como objetivo a redução da ansiedade do grupo, finalizando da forma que foi começada a técnica. Todavia, existe uma diferença entre o primeiro e o último desenho livre, visto que a criação do último é realizada após a mobilização de afetos intensos. Ele oferece dados de como a família se expressa após momentos de estresse e ansiedade. 


\section{Sessão de “devolução" do ADF}

Na sessão seguinte deve-se realizar a "devolução" dos dados recolhidos nos desenhos de cada um. Deve-se, junto com a família, entender os significados simbólicos de cada desenho e interpretá-los. Devido à espontaneidade do desenho, as figuras normalmente expressam sentimentos inconscientes e pensar sobre elas é de alguma forma trazê-los à consciência.

Em sua prática clínica com desenhos, Touson (2002) observou que o ato da criação consiste em três momentos: o da expressão, o da contemplação e o da elaboração. $\mathrm{O}$ da expressão ocorre no momento da criação do desenho. A contemplação ocorre $a$ posteriori, quando a pessoa tem a oportunidade de examinar e considerar com atenção o objeto expressado, reconhecendo-o como próprio e único. O último momento - o da elaboração - envolve a resposta e o insight do sujeito ao que foi expressado no papel e também contemplado.

Pode-se pensar nestes três momentos da criação, observados por aquele autor, e correlacionálos com o ADF. Não seria impróprio afirmar que estes momentos estão presentes na aplicação e na sessão de "devolução" deste instrumento. Na primeira sessão de criação dos desenhos, ocorrem os momentos de expressão e contemplação. Este último envolveria a contemplação familiar em relação aos desenhos de cada membro. Etapa importante de ser observada, pois envolve o "olhar familiar" sobre seu próprio sistema.

Na sessão de "devolução" ocorre a recontemplação e elaboração conjunta sobre os desenhos. A divisão didática proposta por Touson (2002) ajuda a pensar, de forma minuciosa, sobre a riqueza e coerência do ADF; sendo fundamental não só aplicá-lo, mas também interpretá-lo junto à família. O psicoterapeuta, durante a sessão de "devolução", incentiva a família a perguntar algo que gostaria de saber sobre os desenhos uns dos outros. Além disso, incita a família a pensar sobre o simbolismo das figuras desenhadas. As interpretações do psicoterapeuta são feitas somente depois de oferecer este espaço de reflexão para a própria família (Kwiatkowska, 1978).
Ainda na sessão de "devolução", aquela autora recomenda ao psicoterapeuta comparar o primeiro desenho com o último, com a finalidade de analisar como os membros da família se expressaram após passarem por um alto nível de estresse e ansiedade na sessão. Segundo a autora, são os dois desenhos livres que geralmente expressam mensagens mais importantes. A aplicação deste instrumento tem a particularidade de trazer à superfície assuntos que dificilmente seriam discutidos no início de uma psicoterapia, justamente pela possibilidade de o desenho representar os conteúdos inconscientes. Assim, o ADF, como instrumento de avaliação, não só contribui com dados significativos sobre a dinâmica familiar para o processo psicoterápico, mas também acelera a construção da demanda e a adesão ao tratamento.

\section{Método}

Realizou-se um estudo de caso sobre o processo de avaliação da família Cintra com o objetivo de descrever o uso do Arte-Diagnóstico Familiar e a passagem da queixa inicial para a demanda familiar/conjunta. Por meio deste instrumento, buscouse entender a dinâmica inconsciente familiar, considerando-o um facilitador para a explicitação de seus conteúdos.

\section{Participantes}

Participaram deste estudo quatro membros de uma família de nível sócio-econômico baixo, residente numa favela da zona sul do Rio de JaneiroRJ, composta por Ana, uma mulher de 30 anos desempregada, casada com José, um pedreiro de 42 anos, e duas filhas. A mais velha, com oito anos, chama-se Clara e a mais nova, de três anos, Joana. O sobrenome e todos os nomes dos participantes são fictícios para que seja preservada a identidade da família.

\section{Procedimentos}

A família mencionada procurou, pela primeira vez, psicoterapia familiar no Serviço de Psicologia Aplicada (SPA) de uma universidade da cidade do Rio de Janeiro. O material das sessões foi registrado livremente pelos psicoterapeutas em relatórios 
destinados ao SPA. O Termo de Consentimento para utilização do caso em ensino, pesquisa e publicações foi assinado por ambos os pais. Foram realizadas três entrevistas preliminares: a primeira com todos os membros da família; a segunda, para a qual foi convocado o casal, tendo o pai faltado, foi realizada apenas com a mãe; e a terceira apenas com o pai. $\mathrm{Na}$ quarta sessão foi aplicado o ADF a todos os membros da família. Na quinta, foi feita a devolução do material obtido por meio do ADF e das entrevistas anteriores e estabelecido o contrato psicoterapêutico.

Foram descritos dados relevantes que surgiram ao longo das entrevistas preliminares, como o histórico familiar, a queixa inicial, os conflitos e os segredos familiares.

Buscou-se apresentar as descrições dos momentos mais significativos da relação da família ao realizar os desenhos. Além disso, apresentou-se o trabalho realizado na sessão de devolução do material clínico, a partir da aplicação do ADF e das entrevistas preliminares, a fim de ilustrar a necessidade de construção da demanda conjunta para o estabelecimento do trabalho psicoterapêutico.

\section{Resultados e Discussão}

Ana morava em outro estado e migrou para o Rio de Janeiro a fim de trabalhar numa casa de família como babá. Neste período, conheceu José e começou a namorá-lo. Após dois anos de namoro, decidiram morar juntos. Ana aceitou, porque pensava ter encontrado o homem que "pedia a Deus", como dizia. Aqueixa inicial da família Cintra envolvia o fato de Ana não suportar mais as brigas com o marido. José não parecia satisfeito em procurar ajuda psicoterapêutica, pois para ele as brigas não eram um problema. Segundo ele, não sabia o motivo de estar ali e por isso manteve-se monossilábico durante a primeira entrevista.

Ana comentou sobre as brigas e agressões conjugais e também sobre sua depressão. Desejava permanecer constantemente na cama e não tinha motivação para realizar as atividades domésticas. Segundo ela, as brigas do casal interferiam no comportamento das meninas que as presenciavam. Clara teve um aumento em suas crises de asma e não queria comer, e Joana estava muito agitada.
A queixa ficou mais clara quando Ana revelou ter acusado o marido, no Conselho Tutelar, de abuso sexual em relação às duas filhas e por isso não sabia se deveria ou não tê-las trazido à entrevista. Em alguns momentos, Ana questionava-se sobre a veracidade dos abusos, pois de acordo com os exames solicitados pelo Conselho Tutelar, nada foi confirmado. José comentou que sempre deu banho nas meninas e trocou suas fraldas, quando menores, a pedido da mulher. $\mathrm{O}$ casal parecia não se entender no relato dos fatos, José muitas vezes questionou a versão de Ana, mas sem desenvolver seu ponto de vista.

$\mathrm{Na}$ segunda entrevista, Ana compareceu sozinha e decidiu-se por atendê-la, mesmo que individualmente, pois nesta fase inicial de avaliação, quando o enquadre ainda não está estabelecido, entende-se tal situação como um dado relevante para a compreensão da dinâmica familiar. Nestes casos, propõe-se, em seguida, uma entrevista individual para o outro cônjuge.

$\mathrm{Na}$ referida entrevista, Ana revelou que sofreu abuso sexual de um amigo do pai, quando tinha cinco ou seis anos. Segundo a paciente, ele colocava o dedo em sua vagina e a ameaçava, caso contasse para alguém. Seu pai morreu nesta mesma época, algo que foi bastante difícil de superar. Segundo ela, o abuso foi um segredo durante muitos anos, nunca contou para sua mãe e jamais teve coragem de contar para José o ocorrido, com medo de que ele não a compreendesse. Preocupou-se sempre com as filhas e por isso temia deixá-las sozinhas com José, por não confiar nos homens.

As relações sexuais do casal foram afetadas pelo trauma de Ana. Na ocasião da entrevista, essas só ocorriam quando ela procurava o marido, pois sentia-se obrigada a cumprir seu papel de mulher. Não gostava de ser tocada por ele e não considerava normal o homem desejar masturbar uma mulher. Quanto ao suposto abuso de José para com as filhas, Ana comentou não se lembrar se foi ela quem primeiro perguntou a Clara (a filha mais velha) se o pai a tocava, ou se foi Clara quem comentou. Todavia, com Joana, tinha certeza de que foi a filha quem primeiro mencionou, e até mostrou numa boneca a forma de abuso - a mesma sofrida por Ana. 
$\mathrm{Na}$ terceira entrevista, realizada somente com José, este parecia nervoso e quieto. Segundo ele, o problema era o grande envolvimento de Ana com sua família de origem. Ressaltou que embora também tivesse dificuldades com sua família, não as levava para casa. Considerou a denúncia da mulher um absurdo, visto que cuidou durante três anos de Clara, trocando suas fraldas e dando-lhe banho. Afirmou que Ana faz coisas sem pensar, como acusá-lo e depois querer retirar a queixa.

Na sessão posterior à entrevista com José, aplicou-se o ADF. Considerou-se que o uso do instrumento poderia ser uma forma de eles se expressarem, devido à aparente dificuldade de todos para verbalizar seus sentimentos e opiniões conjuntamente. Além disso, pensou-se na possibilidade dos conteúdos gráficos elucidarem dados que pudessem auxiliar as psicoterapeutas na construção, junto com a família, de uma demanda conjunta, tendo em vista a grande resistência e escassa colaboração de José.

\section{Análise dos resultados}

Neste trabalho não foi possível descrever a dinâmica de cada tarefa e cada desenho na medida em que o material ficaria muito extenso. Selecionouse, dentre os desenhos realizados, aqueles que foram mais significativos para ilustrar a passagem da queixa para a demanda familiar e que foram também mais discutidos pelos membros da família. Observou-se uma desmotivação de Ana para desenhar, diferentemente de José, que demonstrava se divertir fazendo as tarefas. No Retrato da família, Clara e José desenharam os membros do casal juntos, parecendo haver, por parte de ambos, uma tentativa de manter a união do casal. No entanto, parecia que seus esforços não estavam sendo eficazes. Ana, ao contrário, desenhou os membros do casal separados, colocandose abaixo do restante da família. Parece que devido ao abuso sofrido na infância, ela não tinha disponibilidade emocional para uma vida conjugal e, assim, inconscientemente, frustrava Clara e José neste desejo de reaproximação do casal.

Pode-se pensar também que Ana se sentia numa posição inferiorizada em relação aos demais, isolando-se do grupo e centrando-se em si mesma. A distância para com a família foi representada no
Primeiro desenho livre, no qual escreveu seu nome e aproveitou as duas letras "A" como olhos de um rosto composto por uma boca sorridente e as sobrancelhas, não havendo o contorno da face.

Clara, no Retrato da família, se representou pela cor amarela. Ana, também usou a mesma cor para desenhar a filha. Na sessão de devolução, pensou-se sobre a possibilidade de a cor amarela ter sido escolhida para representar Clara pelo fato dela ser o membro da família que absorve os conflitos familiares, ficando invisível para não "denunciar" os conflitos. Ela funcionava como porta voz dos problemas do casal: não comia e ficava muito nervosa com as brigas.

No Retrato da família abstrata, buscou-se entender a escolha de determinados símbolos. José fez o desenho de um caminhão para representar a mulher e explicou que fez isso porque acreditava que ela tomava atitudes, muitas vezes, sem olhar, sem ver o que estava fazendo e acabava errando. Devido ao comentário do marido, Ana questionou suas escolhas, como ter deixado o trabalho para cuidar das meninas, não havendo tempo nem para cuidar mais de si.

No Rabisco em conjunto, quinta tarefa do $\mathrm{ADF}$, José pediu diretamente à Clara para desenhar um coração. Talvez o coração dessa família ainda estivesse pulsando, podendo concretizar um pedido de ajuda, representando vida e afetividade. Nesta tarefa, Ana não se envolveu, mostrou-se afastada e indiferente, quem sabe da mesma forma como se representou no Retrato da família. O pai e as duas filhas realizaram essa tarefa com entusiasmo.

Ao observar os desenhos de cada tarefa, podese perceber maior elaboração ao longo do processo. Os primeiros desenhos estavam pequenos e tristes, mas no final pareciam mais coloridos e ricos em detalhes. É possível que, na medida em que foram trabalhando juntos, puderam interagir uns com os outros e se expressaram melhor, enriquecendo-se. Ao comentar isto com a família, todos reconheceram a melhora dos desenhos.

O Arte-Diagnóstico Familiar possibilitou, tanto para as psicoterapeutas quanto para a família Cintra, ver além do discurso manifesto. A partir das entrevistas pôde-se observar que o não comunicável era o mito familiar de abuso, conteúdo, entretanto, que não 
foi observado na aplicação do ADF. A vivência de abuso, contudo, era uma experiência particular de Ana, projetada na relação de José com as filhas. Nos desenhos e nas entrevistas, não foi evidenciado nenhum comprometimento emocional das meninas relativo à situação de abuso sexual. Mesmo assim, os membros desta família estavam enredados no referido mito e compartilhavam inconscientemente o trauma de abuso sexual. A experiência traumática de Ana causava-lhe certo embotamento, impedindo-a de reconhecer a relação afetuosa entre seu marido e suas filhas, assim como de se incluir na afetividade familiar. Na dinâmica familiar, durante a construção do Rabisco em conjunto, o afastamento emocional de Ana é nitidamente expressado em sua recusa de contribuir no desenho.

Merea, Picollo e Zimmerman (2003) concebem o inconsciente familiar como trama relacional e identificatória, a qual sustenta o sistema familiar e funciona como uma memória ou um arquivo do mesmo, e onde são inscritos os mitos. De acordo com estes autores, os mitos são uma série de crenças bem integradas e compartilhadas por todos os membros da família, as quais não são desmentidas pelos que estão implicados nela, apesar da distorção da realidade.

O mito cumpre uma função defensiva que anula o tempo, fazendo parecer como não histórica a crença que o sustenta. $\mathrm{O}$ psicoterapeuta deverá funcionar como aquele que descongela a rigidez defensiva e coloca em marcha a temporalidade. Se o mito não for colocado em palavras ou interpretado não cederá em sua força sintomática (Eiguer, 1985; Ferreira, 1963; Prado, 2000).

Talvez Ana tenha procurado a psicoterapia para a família como uma forma de barrar a transmissão do trauma familiar, de colocar em palavras o mito compartilhado, que impedia a família de se desenvolver, de vivenciar o ciclo de vida. Segundo José, o problema era somente de Ana e do modo como ela se envolvia com os problemas de sua família de origem. Possivelmente, envolver-se com a família de origem relacionava-se de alguma forma com sua fixação na origem/no trauma de abuso, não favorecendo o processo de crescimento familiar, devido à força defensiva atemporal do mito.
As experiências nas famílias de origem têm papel preponderante na transmissão dos mitos familiares (Mossmann, Wagner, \& Féres-Carneiro, 2006). Segundo Magalhães e Féres-Carneiro (2005), o eu conjugal é constituído pela pré-história e história de cada um dos cônjuges. Na conjugalidade deste casal, o mito de abuso manifestou-se por meio de sintomas como o ciúme de José, a desconfiança de Ana e a imaturidade sexual do casal. De alguma forma, José tentava preservar o lugar do casal na família, mas era frustrado por Ana que se afastava e anulava a expressão do marido (desenhando seu rosto de amarelo, quase invisível, na tarefa Retrato da família).

Como já foi mencionada, a presença do olhar e/ou a forma desse olhar, durante a aplicação do instrumento de avaliação, é um aspecto fundamental para a compreensão da dinâmica familiar. Nesta família, não houve troca durante a aplicação, cada um fazia seu desenho e não se interessava em contemplar, nem discutir, a criação dos demais.

A negação do coletivo ficou clara na tarefa do Rabisco em conjunto, na qual houve dificuldade para iniciar a ilustração. É possível que a devolução do Arte-Diagnóstico Familiar, em que houve contemplação familiar em relação aos desenhos de cada um, tenha possibilitado aos membros desta família "olhar" seu próprio sistema e defrontarem-se com seus conflitos e fantasmas.

Será que estes desenhos possibilitaram à Ana pensar em sua responsabilidade na transmissão do mito? No seu afastamento, o qual ficou claro ao não dar nenhuma sugestão na criação do desenho Rabisco em conjunto? Será que olhar para os desenhos da família e para os seus próprios desenhos foi uma oportunidade de encarar seus conflitos e suas questões de origem, como mencionou José?

A queixa inicial de Ana não era compartilhada pelo marido. É possível que para ela, ver-se representada pelos demais como uma pessoa triste e que não pensava, tenha sido a oportunidade de reconhecer seu sofrimento, implicando-se naquilo de que se queixava, intensificando seu desejo de mudança, mesmo que ambivalente. Ao voltar, sozinha, para a sessão seguinte, podendo dar início ao processo psicoterapêutico, Ana pôde mostrar seu desejo de confrontar-se consigo mesma e seus conflitos. 
Uma das funções do psicoterapeuta no período de entrevistas é buscar reduzir a hiper-individualização e cisão entre os membros da família, facilitando a passagem do individual ao conjunto. José não voltou às sessões seguintes: será que não houve esta passagem? Ou será que foi preciso trabalhar a "origem", em Ana, para criar espaço para o conjunto? No início do tratamento, ela demonstrava dificuldade de dividir o setting com as filhas e não as trazia. No entanto, isto foi mudando ao longo do tempo, permitindo a realização de sessões com o subsistema mãe-filhas.

O Arte-Diagnóstico Familiar, como instrumento de avaliação, possibilitou a análise de representações inconscientes da família Cintra, como também das relações familiares. Ao longo da psicoterapia, as ilustrações do instrumento foram fundamentais para as psicoterapeutas nas interpretações, sobretudo aquelas sobre a tristeza e o estado "acamado" de Ana representada por ela e pela filha mais velha, como uma cama, no Retrato da família abstrata.

\section{Considerações finais}

Este trabalho teve como objetivo ilustrar o uso do ADF no trabalho clínico com famílias, analisando-se a especificidade do período de avaliação na psicoterapia de família, especialmente a passagem da queixa inicial da família para a demanda familiar/ conjunta. Por meio da análise do caso clínico foi possível identificar a contribuição do Arte-Diagnóstico Familiar no processo de avaliação, como também a possibilidade de acesso às representações da trama familiar inconsciente, as quais são difíceis de serem expressas em palavras.

Stierlin e cols. (1980/1995) consideram inadequado apontar, diretamente, as facetas da dinâmica familiar na primeira entrevista. Enfatizam que o psicoterapeuta deve tê-las em mente para criar um direcionamento, a fim de que a família possa falar mais adiante, por si mesma, destas questões. A aplicação do Arte-Diagnóstico Familiar, de certa forma, permite que a família as expresse mais rapidamente e de modo menos defensivo. Oferecendo, portanto, material ao psicoterapeuta para futuras in- terpretações, assim como para trabalhar a demanda conjunta, a partir de representações familiares.

Outro aspecto fundamental no período de entrevistas preliminares é a avaliação da dinâmica familiar para que seja trabalhada durante o processo psicoterapêutico. A aplicação do instrumento em questão viabiliza a observação do psicoterapeuta de como a família trabalhará em conjunto e compartilhará as tarefas. No caso clínico apresentado, no Segundo desenho livre, os desenhos de todos os membros foram mais trabalhados, coloridos e ocuparam mais o espaço da folha. Pôde-se identificar que, após a vivência destas tarefas em conjunto, apesar do precário compartilhar coletivo, houve um engajamento, na medida em que "estar em família" possibilitou a todos um amadurecimento de expressão.

A partir deste dado, pôde-se predizer um bom prognóstico para esta família, por mais difícil que tenha sido a aplicação e a presença da insatisfação inicial ao realizar as tarefas. Quanto à observação sobre o enriquecimento dos desenhos - apresentados na última tarefa - trabalharam-se os aspectos funcionais e o benefício de eles poderem estar e sentirem-se em grupo. Assim, a aplicação deste instrumento possibilitou, ao psicoterapeuta e à família, não só identificar os aspectos disfuncionais, mas também os aspectos promotores de saúde, tão importante de serem trabalhados no tratamento.

Ao se trabalhar os recursos funcionais, neste período de avaliação, e conseqüentemente o prognóstico familiar, constrói-se com a família um discurso e um olhar diferentes daqueles apresentados em sua queixa inicial, podendo a mesma adquirir um novo sentido. Dessa forma, ressalta-se a responsabilidade da família na manutenção do sintoma, e ao mesmo tempo, sua capacidade de mudança e de possível evolução onde aparentemente não havia. Assim, com o desenvolvimento deste trabalho, pretendeu-se apresentar subsídios importantes para a prática da psicoterapia de família. É preciso que haja uma profunda discussão sobre o período de avaliação familiar, sua especificidade e seus recursos, posto que estes constituem temas fundamentais para a prática clínica com famílias. 


\section{Referências}

Bleger, J. (2001). Temas de psicologia: Entrevista e grupos (2a ed.). São Paulo: Martins Fontes. (Original publicado em 1980)

Eiguer, A. (1985). Um divã para a família: Do modelo grupal à terapia familiar psicanalítica. Porto Alegre: Artes Médicas.

Féres-Carneiro, T. (2005). Entrevista Familiar Estruturada-EFE: Um método clínico de avaliação das relações familiares. São Paulo: Casa do Psicólogo.

Féres-Carneiro, T. (2008). Clínica de família e casal: Narrando quatro décadas de pesquisa. Revista Brasileira de Terapia Familiar, 1, 91-101.

Féres-Carneiro, T., \& Ponciano, E. L. T. (2005). Articulando diferentes enfoques teóricos na terapia familiar. Revista Interamericana de Psicologia, 39, 439-448.

Féres-Carneiro, T., \& Saba, A. M. F. (1975). Terapia familiar: Teoria e técnica através do estudo de um caso. Arquivos Brasileiros de Psicologia Aplicada, 27, 77-84.

Ferreira, A. J. (1963). Family myth and homeostasis. Archives of General Psychiatry, 9, 457-463.

Kwiatkowska, H. Y. (1971). Family art therapy and family art evaluation: Indication and contraindication. In I. Jakad (Ed.), Psychiatry and art (pp. 53-67). Basel: Karger.

Kwiatkowska, H. Y. (1975). Instruções para conduzir sessões de Arte-Diagnóstico Familiar. Manuscrito não-publicado, Pontifícia Universidade Católica do Rio de Janeiro, Rio de Janeiro, RJ.

Kwiatkowska, H. Y. (1978). Family therapy and evaluation through art. Springfield, IL: Charles C. Thomas.

Lemaire, J. G. (1984). Le couple, sa vie, sa mort. Paris: Payot.

Lemaire, J. G. (2007). L'inconscient dans la famille. Paris: Dunod.
Magalhães, A. S., \& Féres-Carneiro, T. (2005). Conquistando a herança: Sobre o papel da transmissão psíquica familiar no processo da subjetivação. In T. Féres-Carneiro (Org.), Família e casal: Efeitos da contemporaneidade (pp. 24-32). Rio de Janeiro: EdPUC-RJ.

Mannoni, M. (2003). La primera entrevista con el psicoanalista. Barcelona: Gedisa. (Original publicado em 1965)

McGoldrick, M., \& Gerson, R. (1985). Genograms in family assessment. New York: W. W. Norton.

Merea, E. C., Picollo, A. M., \& Zimmerman, E. (2003). La trama familiar y su revelado. In E. C. Merea (Org.), Parejas y famílias: Psiquismo extenso y psicoanálisis intersubjetivo (pp. 9098). Buenos Aires: Lugar.

Morandi, S. B. (2006). A construção da demanda em terapia familiar. Porto Alegre: CEFI. Recuperado em 20 março 2007, de http:// www.cefipoa.com.br/artigos.php?id=1.

Mosmann, C., Wagner, A., \& Féres-Carneiro, T. (2006). Qualidade conjugal: Mapeando conceitos. Paidéia (Ribeirão Preto), 16, 315-325.

Prado, M. C. A. (2000). Destino e mito familiar: Uma questão na família psicótica. São Paulo: Vetor.

Rabelo, A. J. H. (2008). Dificuldades de aprendizagem: O sintoma que denuncia a disfunção do sistema familiar. In R. M. Macedo (Org.), Terapia familiar no Brasil na última década (pp. 312324). São Paulo: Roca.

Rocha, F. J. B. (2000). Do pedido de ajuda à demanda de análise: Sobre escuta psicanalítica e entrevistas preliminares. Alter: Jornal de Estudos Psicodinâmicos, 19, 29-41.

Stierlin, H., Rücker-Embden, I., Wetzel, N., \& Wirsching, M. (1995). Terapia de familia: La primera entrevista ( 2 a ed.). Barcelona: Gedisa. (Original publicado em 1980)

Touson, S. (2002). El dibujo en la terapia: Creación y curación. Buenos Aires: Arenales.

Willi, J. (1993). La pareja humana: Relación y conflicto. Madrid: Morata. 
Artigo recebido em 12/05/2008.

Aceito para publicação em 28/11/2008.

Artigo derivado da monografia de Curso de Especialização em Terapia de Família e Casal da primeira autora, sob a orientação da segunda autora. Caso clínico atendido no Serviço de Psicologia Aplicada da Pontifícia Universidade Católica do Rio de Janeiro pela primeira autora, com supervisão da terceira autora.

Endereço para correspondência:

Profa. Dra. Terezinha Féres-Carneiro. Pontifícia Universidade Católica do Rio de Janeiro. Departamento de Psicologia. Rua Marquês de São Vicente, 225. CEP 22543-900. Rio de Janeiro-RJ, Brasil. E-mail: teferca@puc-rio.br

Rebeca Nonato Machado é mestranda em Psicologia pelo Programa de Pós-graduação em Psicologia Clínica do Departamento de Psicologia da Pontifícia Universidade Católica do Rio de Janeiro, bolsista CNPq.

Terezinha Féres-Carneiro é Professora Titular do Departamento de Psicologia da Pontifícia Universidade Católica do Rio de Janeiro.

Andrea Seixas Magalhães é Professora Assistente do Departamento de Psicologia da Pontifícia Universidade Católica do Rio de Janeiro. 